\title{
Sculpting the $\beta$-peptide foldamer H12 helix via a designed side-chain shape $\dagger$
}

\author{
Anasztázia Hetényi, ${ }^{a}$ Zsolt Szakonyi, ${ }^{a}$ István M. Mándity, ${ }^{a}$ Éva Szolnoki, ${ }^{a}$ Gábor K. Tóth, ${ }^{b}$ \\ Tamás A. Martinek ${ }^{* a}$ and Ferenc Fülöp ${ }^{* a}$
}

Received (in Cambridge, UK) 15th July 2008, Accepted 23rd October 2008

First published as an Advance Article on the web 14th November 2008

DOI: $10.1039 / b 812114 a$

\begin{abstract}
The long-range side-chain repulsion between the $(1 R, 2 R, 3 R, 5 R)$ 2-amino-6,6-dimethyl-bicyclo[3.1.1]-heptane-3-carboxylic acid (trans-ABHC) residues stabilize the $\mathrm{H12}$ helix in $\beta$-peptide oligomers.
\end{abstract}

Synthetic oligomers with distinct conformational preferences (foldamers) are highly intriguing compounds at the interface of covalent and supramolecular (noncovalent) chemistry. ${ }^{1}$ Among foldamers based on remote intrastrand interactions, peptides containing $\beta$-amino acid residues are probably the most thoroughly studied systems. ${ }^{2}$ Their versatile secondary structure patterns and the side-chain controllable conformational preferences are attracting increasing interest. ${ }^{3} \beta$-Peptide oligomers with designed molecular interaction fields have gained a number of biological applications, such as rationally designed antiviral $\mathrm{H} 12$ helices. ${ }^{4}$ In these applications, the helical secondary structures $(\mathrm{H} 14, \mathrm{H} 12$ and $\mathrm{H} 10 / 12)$ play crucial roles with regard to the biological activity; they are induced by the special substitution and stereochemical pattern of the $\beta$-peptide backbone, while the side-chain chemistry is varied independently. The stabilization effects of $\beta$-amino acid residues with cyclic side-chains are indispensable in the $\beta$-peptide helix design. The $\mathrm{H} 12$ helix, which is a good mimic of the $\alpha$-helix in terms of overall shape, can be stabilized by the incorporation of a sufficient number of trans-2-aminocyclopentanecarboxylic acid (trans-ACPC) or the structurally related trans-amino-pyrrolidinecarboxylic acid (trans-APC) residues in the sequence. ${ }^{5}$ Two-thirds of the residues are required to have the side chain topology of a five-membered ring with a trans relative backbone configuration in order to gain a reasonably stable $\mathrm{H} 12$ helix, which imposes considerable limitations on the chemical diversity of the side-chain pattern along these $\beta$-peptide helices. Independent methods to stabilize the $\mathrm{H} 12$ helix are therefore still sought. ${ }^{6}$

In the present work, a novel approach is proposed whereby to induce formation of the $\mathrm{H} 12$ helix. The steric repulsion between the side-chains in positions $i$ and $(i+3)$ was utilized to bias the potential energy landscape, which

${ }^{a}$ Institute of Pharmaceutical Chemistry, University of Szeged, H-6720 Szeged, Hungary.E-mail: martinek@pharm.u-szeged.hu.

E-mail: fulop@pharm.u-szeged.hu; Fax: (+36) 62-545705;

Tel: ( + 36) 62-545768

${ }^{b}$ Department of Medical Chemistry, University of Szeged, H-6720

Szeged, Hungary

$\dagger$ Electronic supplementary information (ESI) available: Experimental details, NMR signal assignments and ${ }^{3} \mathrm{~J}\left(\mathrm{NH}_{i}-\mathrm{C}^{\beta} \mathrm{H}_{i}\right)$ values in $\mathrm{CD}_{3} \mathrm{OH}$ and DMSO- $d_{6}$, ROESY, TOCSY and DOSY spectra for 4, ab initio energies and structures, and complete ref. 16. See DOI: $10.1039 / \mathrm{b} 812114 \mathrm{a}$ eventually destabilizes the $\mathrm{H} 14$ helix in favor of the $\mathrm{H} 12$ helix. We demonstrate here that bulky trans-ABHC residues retain the helical organization of the peptide chain, and the designed interactions facilitate formation of the $\mathrm{H} 12$ helix.

Construction of a H14 helix, the $\beta$-peptide secondary structure most often utilized in biomedical studies, can readily be achieved by using $\beta_{3}$-substituted $\beta$-amino acids in combination with trans2-aminocyclohexanecarboxylic acids (trans-ACHCs). ${ }^{7}$ The cyclic side-chain of the latter lends extra stability to the secondary structure through the restricted conformational space and the $i-(i+3)$ hydrophobic stacking interactions between the cyclohexane rings. ${ }^{8}$ Recent results led to the successful synthesis of monoterpene-derived $\beta$-amino acids with an apopinane skeleton (2-amino-6,6-dimethyl-bicyclo[3.1.1]heptane-3-carboxylic acid; ABHC). ${ }^{9}$ The apopinane moiety is a dimethyl-substituted, methylene-bridged analog of $\mathrm{ACHC}$ and, as such, further enhances the conformational preorganization of the cyclohexane ring, but the bulky substituent certainly disfavors the $i-(i+3)$ hydrophobic stacking interactions in H14 (Fig. 1).

To test the effect of the $i-(i+3)$ steric clash on the preferred secondary structure, oligomers of trans-ABHC were constructed (Scheme 1). Conformational sampling was carried out on $\mathbf{4}$ by using a hybrid molecular dynamics (MD)-Monte Carlo (MC) method and MMFF94x force field. ${ }^{10}$ The lowest energy conformational family was the $\mathrm{H} 12$ helix (32\% of the conformers, average cluster energy relative to the lowest energy conformation: $18.55 \mathrm{~kJ} \mathrm{~mol}^{-1}$ ). Interestingly, the $\mathrm{H} 16$ helix fold was also populated $\left(21 \%, 74.32 \mathrm{~kJ} \mathrm{~mol}^{-1}\right)$, however with higher conformational energies. The $\mathrm{H} 14$ helix was only a low-population high-energy cluster $\left(0.3 \%, 138.37 \mathrm{~kJ} \mathrm{~mol}^{-1}\right)$. Helical structures with combinations of 12-membered and 16-membered $\mathrm{H}$-bonded rings were identified in $22 \%$ of the conformers. Other regular helical fold was not found. All the geometrically possible helices for $\mathbf{1 - 4}, \mathrm{H} 8, \mathrm{H} 10, \mathrm{H} 12, \mathrm{H} 14$, and $\mathrm{H} 16$ were optimized at the $a b$ initio quantum chemistry level (Fig. 2). ${ }^{11}$ The HF/3-21G//B3LYP/6-311G** levels of theory in vacuo were utilized, as this has been reported to provide a good approximation for the $\beta$-peptides. ${ }^{12}$ The structures converged to the corresponding local minimum of the potential energy

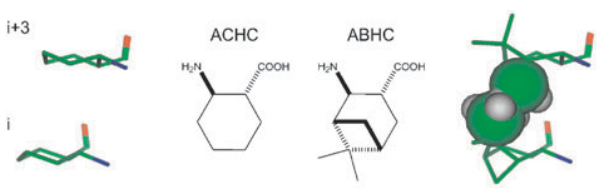

Fig. 1 The steric interactions between side-chains in positions $i-(i+3)$ in the ideal H14 helix for ACHC (no clash) and ABHC (predicted clash) oligomers. 


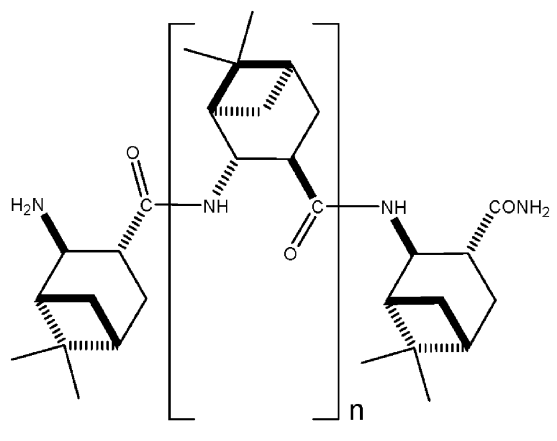

$1, n=1 ; 2, n=2 ; 3, n=3,4, n=4$

Scheme 1 The studied ABHC oligomers.

surface, except for the $\mathrm{H} 10$ helices, which finally converged to $\mathrm{H} 14$.

The modeling indicated that $\mathrm{H} 12$ and $\mathrm{H} 16$ are the most likely secondary structures for $\mathbf{3}$ and $\mathbf{4}$. For $\mathbf{1}$ and $\mathbf{2}, \mathrm{H} 8$ is a low energy fold too. It should be noted that the final ab initio structures of the $\mathrm{H} 12$ helix optimized in vacuo exhibited a 6-membered $\mathrm{H}$-bonded pseudo ring at the $\mathrm{N}$-terminal residue (terminal- $\mathrm{N} \cdot \mathrm{HN}_{2}$ ), though this was not corroborated by the NMR results (see later). These findings support the side-chain repulsion concept for shaping the desired secondary structure.

Model compounds 1-4 were synthesized. The Fmoc$(1 R, 2 R, 3 R, 5 R)$-ABHC stereoisomer was prepared by using literature methods. ${ }^{9}$ The chain assembly was carried out on a solid support, with Fmoc chemistry. The final products were characterized by means of MS and various NMR methods, including COSY, TOCSY and ROESY, in $4 \mathrm{mM} \mathrm{CD} \mathrm{CDH}_{3} \mathrm{O}$ and DMSO- $d_{6}$. In water, severe solubility problems were experienced. The NMR signal dispersions were very good, resonance broadening was not observed, and thus the resonance assignment was achievable.

The time dependence of the residual NH signal intensities in the $\mathrm{N}^{1} \mathrm{H}-\mathrm{N}^{2} \mathrm{D}$ exchange experiments for $\mathbf{4}$ point to the corresponding atoms being considerably shielded from the solvent, due to $\mathrm{H}$-bonding interactions. The proton resonances relating to the terminal amine and the C-terminal amide disappeared immediately after dissolution, whereas the other signals remained for a longer time. The exchange pattern observed is in good agreement with the theoretically predicted H-bonding network of the $\mathrm{H} 12$ helix. For 3, a similar exchange pattern was detected, but the exchange rates were higher, suggesting a less-ordered structure.

For 4, ROESY experiments were run in $\mathrm{CD}_{3} \mathrm{OH}$ and DMSO- $d_{6}$. In DMSO, the characteristic $\mathrm{C}^{\beta} \mathrm{H}_{i}-\mathrm{C}^{\alpha} \mathrm{H}_{i+2}$,

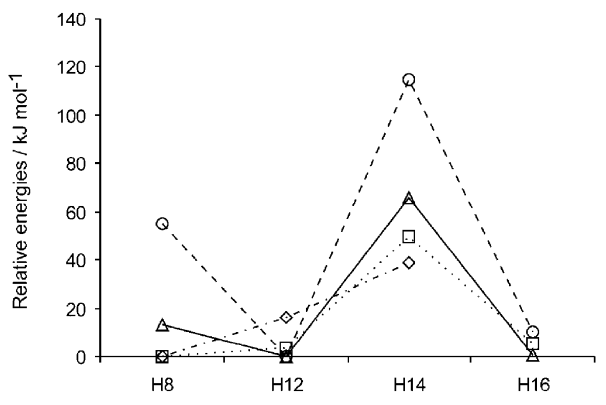

Fig. 2 Relative B3LYP/6-311G** energies (actual energy-lowest energy) of $\mathbf{1}(\diamond), \mathbf{2}(\square), \mathbf{3}(\triangle)$ and $\mathbf{4}(\bigcirc)$ for the ab inito calculated helical secondary structures.
$\mathrm{C}^{\beta} \mathrm{H}_{i}-\mathrm{NH}_{i+2}$ and $\mathrm{Me}_{i}-\mathrm{NH}_{i+3}$ long-range NOE interactions could readily be observed, which unequivocally proves the predicted H12 conformation (Fig. 3 and 4). Hybrid MD-MC modeling with NMR restrains for $\mathbf{4}$ exclusively resulted in the $\mathrm{H} 12$ helix ruling out unfolded structures or other helix types as a predominant conformation. The NOEs between the axial Me groups and amide protons are only due the H12 helix; NOEs of aggregation origin would not be so specific. Although a sufficient number of characteristic NOEs were observed in $\mathrm{CD}_{3} \mathrm{OH}$, some of the long-range ROESY cross-peaks could not be resolved because of the poorer resonance dispersion for the $\mathrm{C}^{\beta} \mathrm{H}_{2-4}$ protons. The $\mathrm{C}^{\beta} \mathrm{H}_{1}-\mathrm{NH}_{3}$ interaction could not be observed, but a weak $\mathrm{C}^{\beta} \mathrm{H}_{1}-\mathrm{NH}_{4}$ cross-peak was detected in both solvents, in full agreement with the $\mathrm{H} 12$ helix formed by the trans-ABHC homo-oligomers. For 3, the long-range NOE interactions characteristic of the $\mathrm{H} 12$ helix could be observed, but $\mathbf{2}$ and $\mathbf{1}$ did not exhibit any helix-related signal.

For 3 and 4, scalar couplings measured on the amide protons indicated values well above $8.5 \mathrm{~Hz}$ in DMSO- $d_{6}$, except for the $\mathrm{N}$-terminal residues, which is in line with the predominantly antiperiplanar $\mathrm{NH}-\mathrm{C}^{\beta} \mathrm{H}$ orientation necessary for the helical structure. For 2, the couplings were decreased significantly, but indicate a prevailing antiperiplanar arrangement for the nonterminal residues, while $\mathbf{1}$ exhibits couplings pointing to random $\mathrm{NH}_{i}-\mathrm{C}^{\beta} \mathrm{H}_{i}$ dihedrals. In $\mathrm{CD}_{3} \mathrm{OH}$, a similar coupling pattern was obtained.

Electronic CD measurements were carried out to gain further evidence in support of the presence of the helical fold determined by NMR. Measurements were carried out in $\mathrm{MeOH}$ only because the ECD spectra in DMSO are not useful for the secondary structural analysis of peptides and proteins, due to interfering absorption from the solvent below $268 \mathrm{~nm}$. In water, solubility problems prevented the measurement. In view of the literature results on the extreme sensitivity of the ECD to small changes in the foldamer geometry, ${ }^{13}$ and of the UV absorbance of the asymmetric cyclobutane moiety in the range $190-250 \mathrm{~nm},{ }^{14}$ the direct comparison with the literature ECD fingerprints of the H14 and $\mathrm{H} 12$ helices obtained for various UV inactive side-chains is not possible. ${ }^{15}$ Unfortunately, CD result was not published for the only known $\beta$-peptide helix having cyclobutane fragment in the side-chain. ${ }^{6}$

The ECD spectra revealed a significant chain length-dependence (Fig. 5). The positive lobes display a maximum at around $220 \mathrm{~nm}$ for $\mathbf{1}$ and 2, while the band is shifted to $210 \mathrm{~nm}$ and $205 \mathrm{~nm}$ for 3 and 4, respectively. The position of the negative band remains constant at around $195 \mathrm{~nm}$. The continuous hypsochromic displacement of the positive band and the increasing symmetry of the

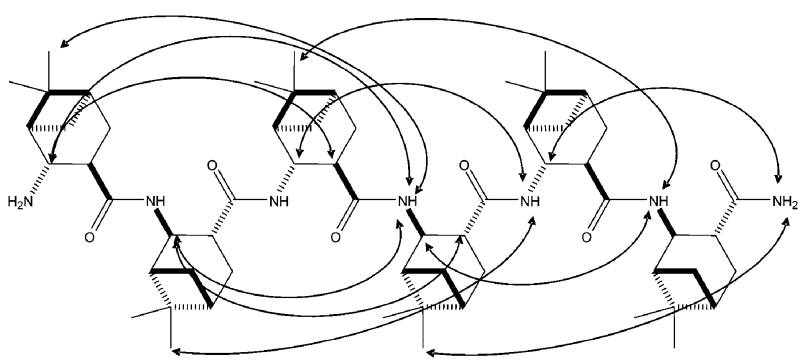

Fig. 3 Resolvable long-range NOE interactions detected in the ROESY spectrum of $\mathbf{4}$ in DMSO- $d_{6}$. 


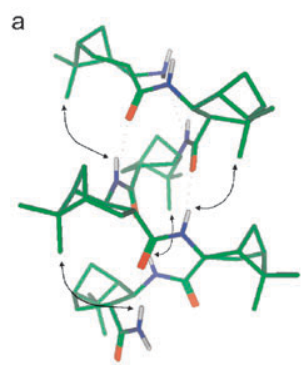

b

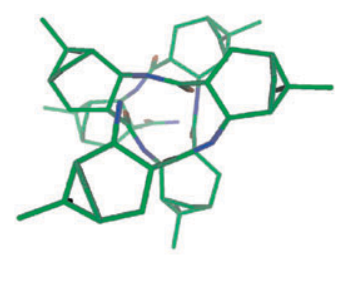

Fig. 4 Side view (a) and top view (b) of the NMR-derived H12 helix formed by 4 . Arrows indicate only the $\mathrm{Me}_{i}-\mathrm{NH}_{i+3} \mathrm{NOEs}$ out of the many long-range interactions observed in the ROESY spectra of $\mathbf{4}$ (see Fig. 3).

positive couplet unambiguously indicate that the folding takes place in a chain length-dependent fashion, which is an essential feature of the helix formation. Foldamers $\mathbf{2}$ and $\mathbf{3}$ display higher intensities at short wavelengths, which might indicate a partial population of an elongated structure such as H8 helix. ${ }^{16}$

Experimental ${ }^{17}$ and theoretical ${ }^{18}$ studies and our own earlier results ${ }^{19}$ indicate that self-association in the solution phase is an inherent feature of the horizontally or vertically amphiphilic $\beta$-peptide foldamers. To test this phenomenon, DOSY NMR spectra were run and the aggregation numbers were determined in $\mathrm{CD}_{3} \mathrm{OD}$ from the measured diffusion constants for $\mathbf{3}$ and $\mathbf{4}$ in the same way as described earlier. ${ }^{20}$ In the present work, glucose was utilized as external reference. The average aggregation numbers for $\mathbf{3}$ and $\mathbf{4}$ were 8.6 and 13.9, respectively. Since no head-to-tail NOE was detected for these foldamers, the sideby-side helix bundle type association is likely. This result reveals that the $\mathrm{H} 12$ helix constructed from the trans-ABHC residues is capable of self-association, in agreement with the slowness of the $\mathrm{NH} / \mathrm{ND}$ exchange due to the extra shielding.

In the present work, a newly synthesized apopinene-derived $\beta$-amino acid monomer (trans-ABHC) was utilized, which has a special side-chain shape preventing $i-(i+3)$ hydrophobic side-chain stacking interactions. The NMR, ECD and $a b$ initio modeling evidences unequivocally prove that the $\mathrm{H} 12$ helix is the prevailing conformation for these residues, and the folding takes place in a chain length-dependent manner. Diffusionordered NMR spectroscopy demonstrated that the secondary structure formation in $\mathrm{MeOH}$ is accompanied by a selfassociation phenomenon, driven by hydrophobic interactions.

We believe that the trans-ABHC residues incorporated in $i-(i+3)$ positions in the $\beta$-peptide sequence should be able to

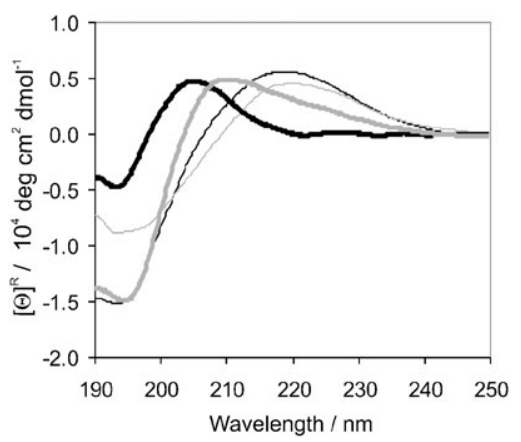

Fig. 5 ECD curves measured for 1 (thin gray), 2 (thin black), 3 (thick gray), and $\mathbf{4}$ (thick black). force formation of the $\mathrm{H} 12$ helix even if open-chain $\beta_{3}$-amino acid residues are present in the structure, which would thereby afford a novel route to the building of this intriguing helix type. A study to test this feature is in progress.

We thank the Hungarian Research Foundation (OTKA No. NF69316) and ALAP4-00092/2005 for financial support. Z.S. and T.A.M. acknowledge the János Bolyai Fellowship from the HAS. We thank Dr Ilona Lackó for help with the ECD.

\section{Notes and references}

1 P. Le Grel and G. Guichard, In: Foldamers: Structure, Properties and Applications: Foldamers Based on Remote Intrastrand Interactions, eds. S. Hecht, I. Huc, Wiley-VCH, 2007, pp. 35-74.

2 C. M. Goodman, S. Choi, S. Shandler and W. F. DeGrado, Nature Chem. Biol., 2007, 3, 252-262.

3 (a) R. P. Cheng, S. H. Gellman and W. F. DeGrado, Chem. Rev., 2001, 101, 3219-3232; (b) D. Seebach, A. K. Beck and D. J. Bierbaum, Chem. Biodiversity, 2004, 1, 1111-1239; (c) T. A. Martinek and F. Fülöp, Eur. J. Biochem., 2003, 270, 3657-3666; (d) R. P. Cheng, Curr. Opin. Struct. Biol., 2004, 14, 512-520.

4 E. P. English, R. S. Chumanov, S. H. Gellman and T. J. Compton, Biol. Chem., 2006, 281, 2661-2667.

5 D. H. Appella, L. A. Christianson, D. Klein, D. A. Powell, D. R. Powell, X. Huang, J. J. Barchi and S. H. Gellman, Nature, 1997, 387, 381-384.

6 J. D. Winkler, E. L. Piatnitski, J. Mehlmann, J. Kasparec and P. H. Axelsen, Angew. Chem., Int. Ed., 2001, 40, 743-745.

7 (a) T. L. Raguse, J. R. Lai and S. H. Gellman, Helv. Chim. Acta, 2002, 85, 4154-4164; (b) D. Seebach, A. Jacobi, M. Rueping, K. Gademann, M. Ernst and B. Jaun, Helv. Chim. Acta, 2000, 83, 2115-2140.

8 D. Seebach, S. Abele, K. Gademann, G. Guichard, T. Hintermann, B. Jaun, J. L. Matthews and J. V. Schreiber, Helv. Chim. Acta, 1998, 81, 932-982.

9 Z. Szakonyi, T. A. Martinek, R. Sillanpää and F. Fülöp, Tetrahedron: Asymmetry, 2008, 19, 2296-2303.

10 (a) T. A. Halgren, J. Comput. Chem., 1996, 17, 490-512; (b) T. A. Halgren, J. Comput. Chem., 1999, 20, 720-729.

11 M. J. Frisch, et al., GAUSSIAN 03 (Revision C.02), Gaussian, Inc., Pittsburgh, PA, 2004. http://www.gaussian.com.

12 (a) T. Beke, I. G. Csizmadia and A. Perczel, J. Comput. Chem., 2004, 25, 285-307; (b) K. Mohle, R. Gunther, M. Thormann, N. Sewald and H. J. Hofmann, Biopolymers, 1999, 50, 167-184.

13 X. Daura, D. Bakowies, D. Seebach, J. Fleischhauer, W. F. van Gunsteren and P. Krüger, Eur. Biophys. J., 2003, 32, 661-670.

14 (a) H. T. Kim and J. K. Park, Polym. Bull., 1998, 41, 325-331; (b) B. Skalski, M. Rapp, M. Suchowiak and K. Golankiewicz, Tetrahedron Lett., 2002, 43, 5127-5129.

15 A. Glatti, X. Daura, D. Seebach and W. F. Gunsteren, J. Am. Chem. Soc., 2002, 124, 12972-12978.

16 (a) Abele, P. Seiler and D. Seebach, Helv. Chim. Acta, 1999, 82, 1559-1571; (b) R. Threlfall, A. Davies, N. M. Howarth, J. Fisher and R. Cosstick, Chem. Commun., 2008, 585-587.

17 (a) W. C. Pomerantz, V. M. Yuwono, C. L. Pizzey, J. D. Hartgerink, N. L. Abbott and S. H. Gellman, Angew. Chem., Int. Ed., 2008, 47, 1-5; (b) E. J. Petersson and A. J. Schepartz, J. Am. Chem. Soc., 2008, 130, 821-823; (c) Z. Yang, G. Liang, M. Ma, Y. Gao and B. Xu, Small, 2007, 3, 558-562; (d) B. Jagannadh, M. S. Reddy, C. L. Rao, A. Prabhakar, B. Jagadeesh and S. Chandrasekhar, Chem. Commun., 2006, 4847-4849; (e) F. Rua, S. Boussert, T. Parella, I. Diez-Perez, V. Branchadell, E. Giralt and R. M. Ortuno, Org. Lett., 2007, 9, 3643-3645.

18 T. Beke, I. G. Csizmadia and A. Perczel, J. Am. Chem. Soc., 2006, 128, 5158-5167.

19 (a) T. A. Martinek, A. Hetényi, L. Fülöp, I. M. Mándity, G. K. Tóth, I. Dékány and F. Fülöp, Angew. Chem., Int. Ed., 2006, 45, 2396-2400; (b) T. A. Martinek, I. M. Mándity, L. Fülöp, G. K. Tóth, E. Vass, M. Hollósi, E. Forró and F. Fülöp, J. Am. Chem. Soc., 2006, 128, 13539-13544.

20 A. Hetényi, I. M. Mándity, T. A. Martinek, G. K. Tóth and F. Fülöp, J. Am. Chem. Soc., 2005, 127, 547-553. 